\title{
The Role of Veterinarians in a Foundation for Elderly Dogs
}

\author{
Ronald Lagoe $^{1^{*}}$, Alyssa Chandler ${ }^{2}$, Christine Berry ${ }^{3}$ \\ ${ }^{1}$ The Ruthie Foundation, Camillus, NY, 13031, USA \\ ${ }^{2}$ DVM, Cornell University Hospital for Animals, Ithaca, NY, 14851, USA \\ ${ }^{3}$ BS, Liverpool Animal Health Center, Liverpool, NY, 13090, USA
}

Received: 7 April, 2017; Accepted: 6 May, 2017; Published: 16 May, 2017

*Corresponding author: Ronald Lagoe, PhD, The Ruthie Foundation, Camillus, NY, 13031, USA; Tel: (315) 464-4368: E-mail: hospexcl@cnymail.com

\section{Introduction}

In recent years, interest in the care of elderly dogs has increased in the United States. Advances in veterinary medicine have prolonged the life spans of the animals that it supports.

The needs of elderly dogs have generated interest among many specialties within veterinary medicine. These include internal medicine, surgery, anesthesiology, neurology, orthopedics, dermatology, and ophthalmology. This process has occurred in university teaching hospitals and private practices $[1,2]$.

This evolution of clinical practice has been supported by funding from veterinary providers and dog owners. Unlike in the case of human health care, this has not been accompanied by the development of large third party payers. As a result, a number of relatively small insurance plans and private organizations have emerged to address these needs.

\section{Development of the Organization}

This communication described the roles of veterinarians in the development and operation of a small private foundation supporting the care of elderly dogs. This organization, The Ruthie Foundation, is named after Ruthie, a black and tan miniature dachshund who overcame numerous obstacles in her lifetime, which spanned more than 20 years.

The Ruthie Foundation was organized by her owner and a group of veterinarians at a practice in Syracuse, New York and the Cornell University Hospital for Animals. A short time after Ruthie's passing in 2014, they incorporated The Foundation as a 501(C) (3) tax exempt organization.

Five veterinarians and Ruthie's owner comprised the six member Board of Directors of the Foundation. Through their participation, a law firm in Syracuse prepared the incorporation papers and tax exempt status application for the Foundation at a discounted cost.

\section{Operation of the Organization}

The operation of The Ruthie Foundation was developed to make the most efficient use of limited resources. The organization has no paid staff.

The veterinarians and Ruthie's owner, who comprised the Board of Directors, contributed the time and initial funding necessary to begin providing services. This process included a number of important roles.

One of these roles included raising revenue necessary to develop a website for the Foundation and limited financial assistance for caregivers of elderly dogs. The website provided a mechanism for the Foundation to receive contributions. It can be accessed at theruthiefoundation.com.

Another role of the veterinarians who comprised The Ruthie Foundation Board of Directors was to support development of a second website to provide information to caregivers of elderly dogs. The information in this website was developed by the veterinarians who served on the Board of Directors, as well as other veterinarians at the Cornell University Hospital for Animals. Its content addressed internal medicine, neurology, oncology, orthopedics, nutrition, ophthalmology, and other specialties. This website can be accessed at careforgeriatricdogs.com.

Perhaps the most important role of the veterinarians in the operation of The Ruthie Foundation was the identification of elderly dogs and their owners who were candidates for support. This function was carried out by the veterinarians who comprised the Board of Directors and through referrals from other veterinarians in the Central New York area. A veterinary technician who functioned as a coordinator at one of the participating practices made important contributions to this process.

The identification of candidates for Foundation support was based on the clinical and social skills of participating veterinarians and the technician. It involved identification of the care needs of dogs defined by practitioner visits, tests, and medications. It also included evaluation of the ability of owners to meet these needs with available resources. Through this process, candidates for support from the Foundation were identified so that care, which otherwise might not be available, could be provided to them. 
The ongoing coordination of Foundation activities has been carried out by Ruthie's owner, a volunteer staff, in cooperation with the participating veterinarians. This process has included the referral of elderly dogs identified for support by the organization to veterinary care at participating practices. Ruthie's owner and the participating veterinary technician have been responsible for collection of information concerning the treatment of patients and for distribution of funds for this care. In most cases, funding has been provided to the veterinary practices involved.

Much of this care has been developed through the efforts of the veterinary technician as coordinator of care in the practice where most Foundation dogs have received care. She has provided a full range of volunteer support including patient identification, coordination with veterinarians, and distribution of funds.

Another important role for veterinarians associated with The Ruthie Foundation has been the provision of care by specialists at the Cornell University Hospital for Animals. This process has included the review of patient records by the Department of Internal Medicine as well as examination and followup by a number of departments at the Hospital. Though this process, the Foundation has been able to coordinate a high level of specialty care for the elderly dogs that it supports.

As the Ruthie Foundation has evolved, it has made contacts with additional veterinarians and veterinary technicians at private practices and the Cornell University Hospital for Animals. These contacts have made it possible to extend both the organization's efforts to provide care for elderly dogs and Ruthie's legacy.

\section{Results}

This communication described how a small foundation to support extended care for elderly dogs has been developed and operated. Through the work of participating veterinary staff, The Ruthie Foundation was able to generate \$9,719 in 2015 and 8,230 in 2016 for care of eleven elderly dogs. Approximately 95 percent of its revenue was devoted to direct patient care.

\section{References}

1. Baetge CL, Matthews NS. Anesthesia and Analgesia for Geriatric Veterinary Patients. Vet Clin North Am Small Anim Pract. 2012;42(4):643-53, v. doi: 10.1016/j.cvsm.2012.05.001

2. Larsen JA, Farcas A. Nutrition of Aging Dogs. Veterinary Clinics of North America: Small Animal Practice. 2014;44(4):741 -759. 